JPE 11-1-14

\title{
High Efficiency Alternating Current Driver for Capacitive Loads Using a Current-Balance Transformer
}

\author{
Jong-Bok Baek* , Bo-Hyung Cho*, and Joung-Hu Park ${ }^{\dagger}$ \\ * Dept. of Electrical Eng. \& Computer Sci., Seoul National University, Seoul, Korea \\ ${ }^{\dagger}$ Dept. of Electrical Eng., Soongsil University, Seoul, Korea
}

\begin{abstract}
This paper proposes a new alternating current driving method for highly capacitive loads such as plasma display panels or piezoelectric actuators, etc. In the proposed scheme, a current balance transformer, which has two windings with the same turnratio, provides not only a resonance inductance for energy recovery but also a current balance among all of the switching devices of the driver for current stress reduction. The smaller conduction loss than conventional circuits occurs due to the dual conduction paths which are parallel each other in the current balance transformer. Also, the leakage inductances of the transformer are utilized as resonant inductors for energy recovery by the series resonance to the capacitive load. Furthermore, the resonance contributes to the small switching losses of the switching devices by soft-switching operation. To confirm the validity of the proposed circuit, prototype hardware with a 12-inch mercury-free flat fluorescent lamp is implemented. The experimental results are compared with a conventional energy-recovery circuit from the perspective of luminance performances.
\end{abstract}

Key Words: Capacitive load, Current balance transformer, Energy recovery, Mercury-free fluorescent lamp, Soft-switching

\section{INTRODUCTION}

Recently, some electronic-engineered applications with capacitive load characteristics have appeared in the market such as plasma displays and ceramic actuators, etc. The inherent capacitance can cause a large power loss by hard-switching charge-dissipation in alternating current (AC) driving operation. Since the dissipation loss increases by the capacitance and the square of the charging voltage as $\mathrm{CpVs}^{2}$, high voltage applications require extensive circuit designs in order to obtain a high operating efficiency. Some of the most prevailing applications are in the plasma area particularly in the display industry. A Plasma Display Panel (PDP) has several tens / hundreds nano Farad $(\mathrm{nF})$ capacitive loads and a greater than $200 \mathrm{kHz}$ switching cycle, demanding a well-designed driver circuit employing a resonant switching network for avoiding charge dissipation. Another newly-emerging application in the plasma display area is the flat panel display mercury-free flat fluorescent lamp (MFFL) [1]-[6], which has several kilo-volt (KV) AC driving with a $10-50 \mathrm{kHz}$ operating frequency. Since the capacitive load holds a charging energy which can cause a power loss at the discharging moment, the discharging condition is the primary cause of decreased efficiency in a high

Manuscript received Feb. 1, 2010; revised Nov. 4, 2010

$\dagger$ Corresponding Author: wait4u@ssu.ac.kr

Tel: +82-2-814-7965, Fax: +82-2-817-7961, Soongsil University

* Dept. of Electrical Eng., \& Computer Sci., Seoul National University, Seoul,Korea frequency drive. Therefore, an AC driver circuit design with a charged-energy recovery function is quite critical to high efficiency realization [7]-[18].

Webber's energy recovery circuit (ERC) which employs a natural series resonance is one of the most popular schemes in the industry [7]. Fig. 1 shows the basic architecture of a Webber's conventional ERC and its key waveforms. Through a series resonance between the inductor and the capacitive load, the panel voltage softly changes into three levels such as a positive source (Vs), a negative source (-Vs), and zero. This ERC also uses auxiliary capacitors $\mathrm{C}_{1}, \mathrm{C}_{2}$ to inject and to recover the charge in the load capacitance $\mathrm{C}_{\mathrm{p}}$. Since the auxiliary capacitors $C_{1}$ and $C_{2}$ in fig. 1(a) have parameters that are approximately ten times greater than the equivalent panel capacitance, they operate as a constant voltage source. The steady-state voltage maintains a neutral point at Vs/2 because the recovery and injection energy have the same amount in a period.

However, there are potential areas for further improvements such as the energy recovery efficiency and the complexity of the driving circuit. It has a high conduction loss due to the series-connected bidirectional switch networks and the possibility of an in-rush current as a result of a failure in the zero voltage switching (ZVS) due to a voltage drop from the MOSFET's parasitic resistance as shown in fig. 2(b). Sometimes, a failure in the zero current switching (ZCS) also occurs due to a short circuit in the resonant time period. From 


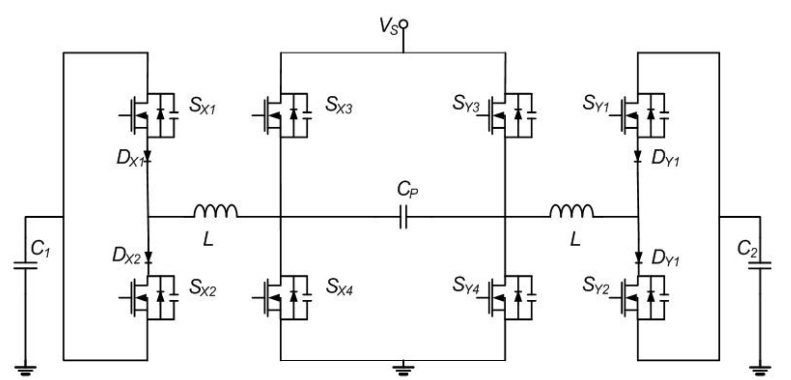

(a) Circuit diagram.
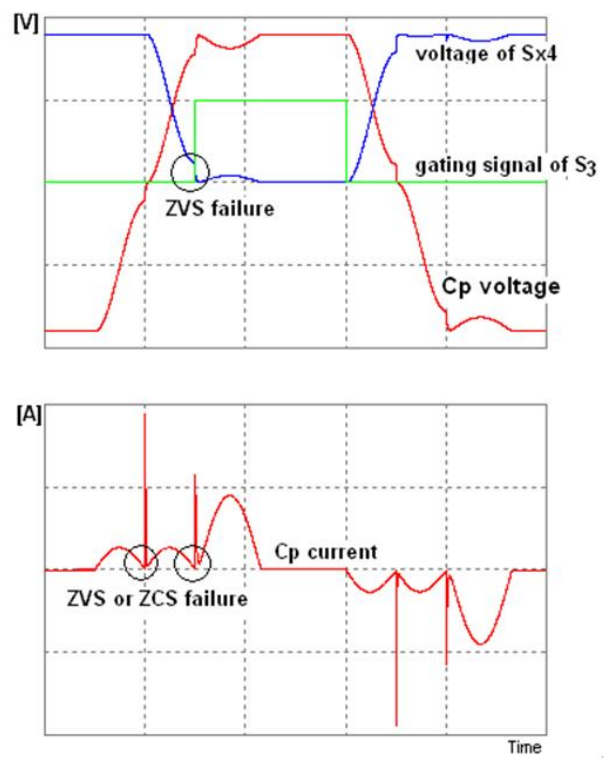

(b) Voltage and current waveforms of Weber's ERC.

Fig. 1. Conventional Webber's ERC [7], [19].

the perspective of part count, it needs extra diodes to block the bi-polar (AC) voltage on the resonant circuit branches.

In this paper, a new ERC using a current-balance transformer is proposed to improve the energy recovery efficiency and to reduce the part count of the driving circuit. Each operating mode of the proposed ERC is explained in the following sections. A hardware prototype using a 12-inch MFFL is implemented to verify the circuit operation. Its luminance performance is compared with a conventional Webber's ERC, as well. Experimental result indicates that under an operating range with a normal luminance area, the luminance efficiency is increased by $15 \%$.

\section{ENERgy ReCOVERy Circuit With CURRENT-BALANCE TRANSFORMER}

The operating sequence of the proposed energy recovery circuit is quite similar to that of other conventional ERCs: capacitive load charging, sustaining, energy recovery, and holding. This ERC introduces series resonance in the energy recovery modes, which is similar to the Webber's circuit. Fig. 2 shows a circuit diagram of the proposed ERC. Two currentbalance transformers are located between a couple of fullbridge legs. It has a symmetric structure so that the load is located between the two current-balance transformers of the twin full-bridges for AC bipolar operation. The turn-ratio of a

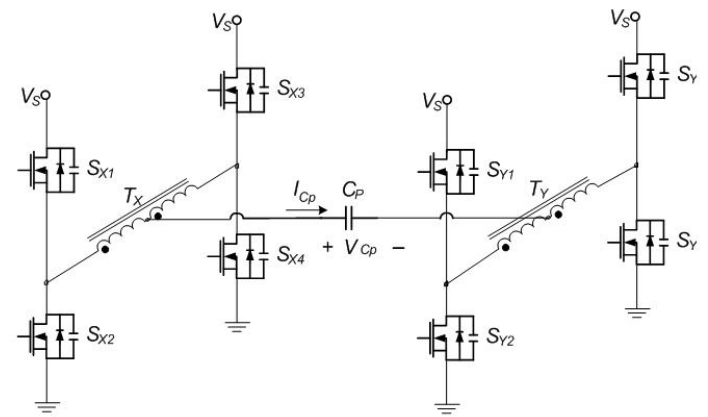

Fig. 2. Proposed AC driving energy recovery circuit with a current balance transformer.

current-balance transformer is generally $1: 1$ to exactly balance the primary and secondary winding currents.

From the current-balance transformer, the load current is equally split into each winding during every operating moment. Therefore, at all times, the current flows not through a single switch leg but through both switch legs simultaneously, leading to the conduction loss being reduced by half. Because of the current sharing operation between the switching devices in the proposed scheme, the voltage and current stresses are exactly the same for all of the switches, which results in the same device part number leading to enormous benefits for mass production.

It also reduces the possibility of soft-switching failure at the moment of switching turn-on because the equivalent series resistances (ESRs) on the switching legs dissipate the resonant energy circulating for the soft-switching. The in-rush current caused by a soft-switching failure at the beginning of a sustain discharge is a critical factor not only for the power efficiency, but also for the electromagnetic interference (EMI) and the device life-span [19]. In the proposed scheme, the circuit has a lower chance of being exposed to a failure due to a reduced ESR. Even with the EMI and a high frequency ringing at the switching legs, the current-balance transformer performs as a high-frequency rejection filter for sustaining the load in the proposed scheme. Finally, since the proposed ERC includes no additional diodes for supporting the MOSFET's unidirectional conduction and no extra inductor replaced with transformer leakage inductances [20], the circuit is competitive from the perspective of part count and manufacturing cost. On the other hand, a conventional ERC requires a pair of bidirectional voltage blocking switch cells including some high currentrating diodes, which increases the part count when compared with the proposed scheme.

Fig. 3 shows the operating sequences (gating signals of $\mathrm{S}_{\mathrm{X} 1}-$ $\mathrm{S}_{\mathrm{Y} 4}$ ) and the key waveforms of the proposed ERC. As shown in Fig. 3, there are 8 distinct operating modes in a cycle, and the second-half of a single cycle is identical to the first-half.

\section{A. Operating Mode Analysis}

- Mode $1\left[\mathrm{t}_{0}<\mathrm{t} \leq \mathrm{t}_{1}\right]$ :

Before $t_{0}$, all of the bottom switches $\left(\mathrm{S}_{\mathrm{X} 2}, \mathrm{~S}_{\mathrm{X} 4}, \mathrm{~S}_{\mathrm{Y} 2}, \mathrm{~S}_{\mathrm{Y} 4}\right)$ are in the turn-on state and the panel voltage $\left(\mathrm{V}_{\mathrm{Cp}}\right)$ is zero. The load current $\left(\mathrm{I}_{\mathrm{Cp}}\right)$ is also zero at $\mathrm{t}_{0}$. At the beginning of mode $1, \mathrm{~S}_{\mathrm{X} 1}$ (or $\mathrm{S}_{\mathrm{X} 3}$ ) turns on and $\mathrm{I}_{\mathrm{Cp}}$ start to flow through both of 


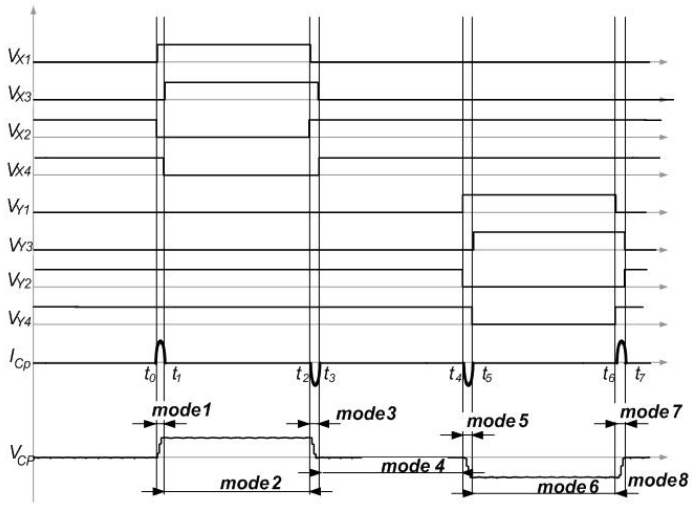

Fig. 3. Key waveforms of the proposed ERC in 3-level AC driving.

the switching legs of $\mathrm{S}_{\mathrm{X} 1}$ (or $\mathrm{S}_{\mathrm{X} 3}$ ) and $\mathrm{S}_{\mathrm{X} 4}$ (or $\mathrm{S}_{\mathrm{X} 2}$ ) because of the current balance transformer. The current conducts on the other bridge, spliting through $\mathrm{S}_{\mathrm{Y} 2}$ and $\mathrm{S}_{\mathrm{Y} 4}$ as well. Due to the parallel conduction path, the equivalent resistance of the switching leg is reduced to half of the single MOSFET drainsource resistance. The conducting current resonates through the leakage inductance of the transformer $(\mathrm{L})$ and the panel capacitance ( $\mathrm{Cp}$ ) as in equation (1). The equivalent circuit during the operating mode is shown in Fig. 4(a). The arrow indicates the conducting current direction.

The load voltage $\mathrm{V}_{\mathrm{Cp}}$ reaches $\mathrm{V}_{\mathrm{S}}$, then $\mathrm{S}_{\mathrm{X} 3}$ (or $\mathrm{S}_{\mathrm{X} 1}$ ) turns on in mode 2. In terms of the other bridge, both $\mathrm{S}_{\mathrm{Y} 2}$ and $\mathrm{S}_{\mathrm{Y} 4}$ maintain the on-state, which holds the $\mathrm{T}_{\mathrm{Y}}$ tap voltage to the ground. At the end of mode $1, \mathrm{~S}_{\mathrm{X} 4}$ (or $\mathrm{S}_{\mathrm{X} 2}$ ) turns off under an almost zero-current switching condition due to the resonant conduction current. The anti-parallel diode has no reverse recovery at the switching-off instant.

The load voltage $\left(V_{C p}\right)$ increases from zero to $V_{S}$ under the resonance between the leakage inductance $L$ and the load $C_{p}$. The load voltage and the current equations are:

$$
\begin{gathered}
V_{C p}=\frac{V_{S}}{2}\left(1-\cos \omega_{0}\left(t-t_{0}\right)\right) \\
I_{C p}=\frac{V_{S}}{2 Z_{0}} \sin \omega_{0}\left(t-t_{0}\right)
\end{gathered}
$$

where, $\omega_{0}=\frac{1}{\sqrt{L C_{p}}} Z_{0}=\sqrt{\frac{L}{C_{p}}}$.

- Mode $2\left[\mathrm{t}_{1}<\mathrm{t} \leq \mathrm{t}_{2}\right]$ :

In the previous mode, $\mathrm{S}_{\mathrm{X} 4}$ (or $\mathrm{S}_{\mathrm{X} 2}$ ) turns off along with the soft-switching of the anti-parallel diode. Mode 2 starts when $\mathrm{V}_{\mathrm{Cp}}$ reaches $\mathrm{V}_{\mathrm{S}}$. At that moment, the anti-parallel diode of $\mathrm{S}_{\mathrm{X} 3}$ (or $\mathrm{S}_{\mathrm{X} 1}$ ) starts to join the load current conduction and $S_{X 3}$ (or $S_{X 1}$ ) turns on under the ZVS condition. The conducting MOSFETs of the $\mathrm{Y}$ board are still connected to the ground and those of the $\mathrm{X}$ board are connected with the power source VS. The actual load discharge occurs during this mode. From the current sharing, the conduction loss also decreases significantly. Fig. 4(b) shows the current sharing path in this mode.

- Mode $3\left[\mathrm{t}_{2}<\mathrm{t} \leq \mathrm{t}_{3}\right]$ :

During this time, the load voltage starts to decrease and the stored energy in the load capacitance is recovered. The

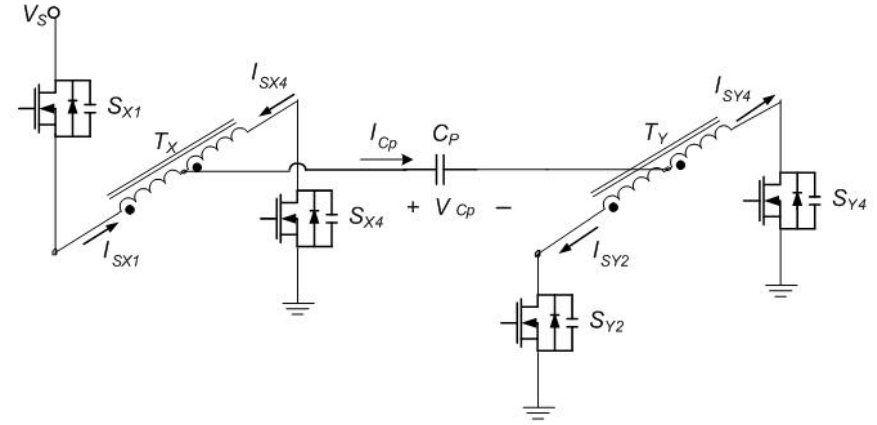

(a) Mode 1 .

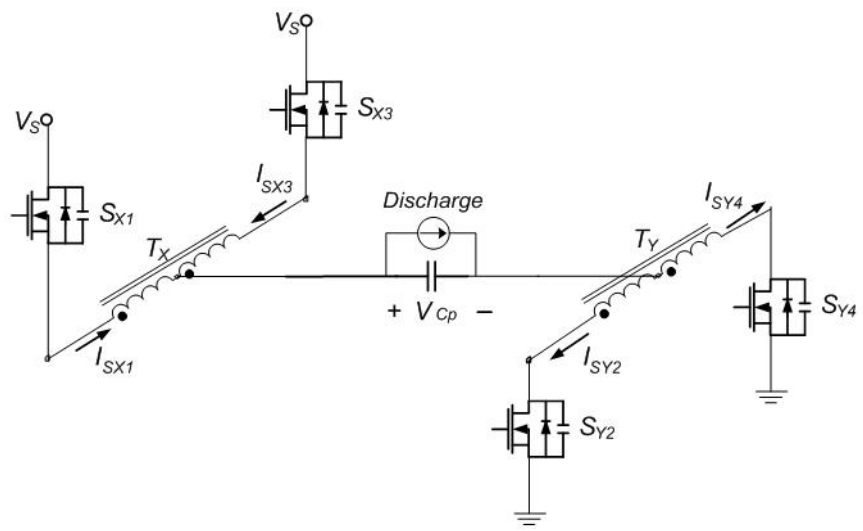

(b) Mode 2 .

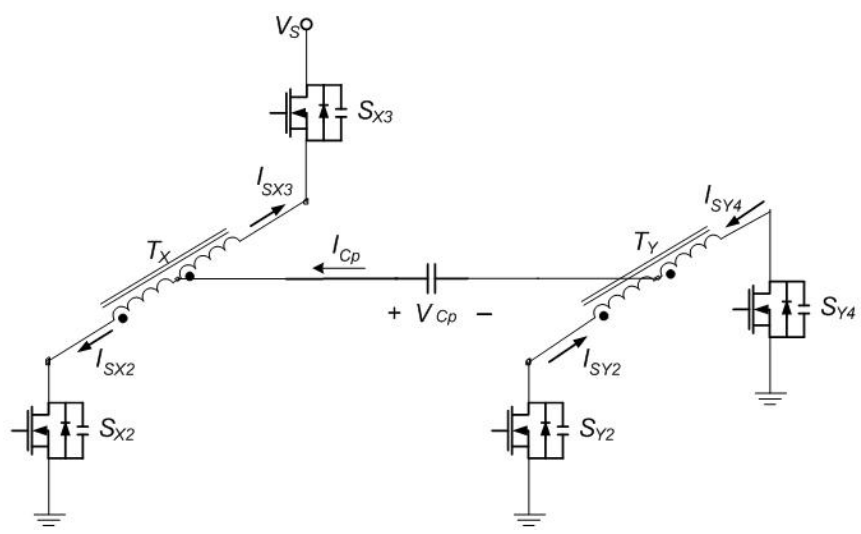

(c) Mode 3 .

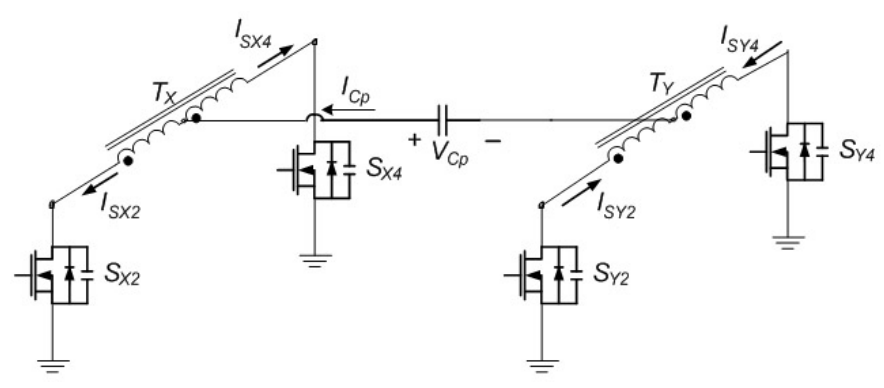

(d) Mode 4.

Fig. 4. Operational mode circuit diagrams of the proposed ERC. 


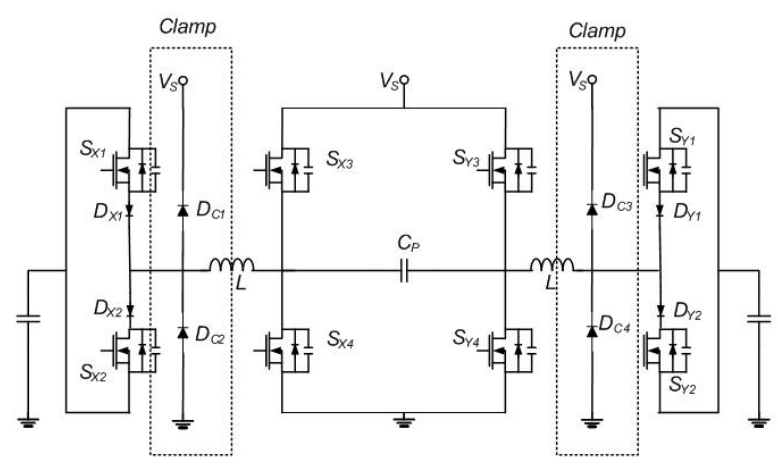

Fig. 5. An example of Weber's ERC with a voltage-clamp circuit [7], [21].

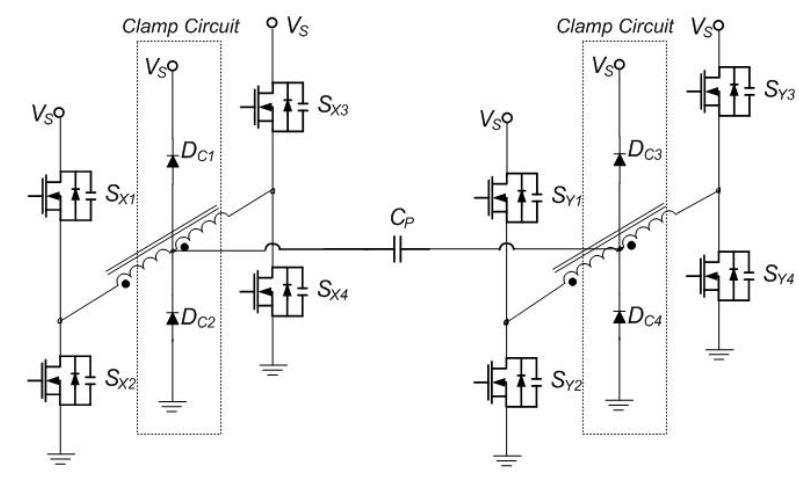

Fig. 6. An example of the proposed ERC with a voltage-clamp circuit.

operation is quite similar to mode 1 except for the turning on of $S_{X 2}$ (or $S_{X 4}$ ) for the energy recovery path of the load charge. The $\mathrm{Y}$ board is still tied on ground. When $\mathrm{S}_{\mathrm{X} 2}$ (or $\left.\mathrm{S}_{\mathrm{X} 4}\right)$ turns on, the stored charges in the load start to move back to the power source through $S_{X 2}$ (or $S_{X 4}$ ) and $S_{X 3}$ (or $S_{X 1}$ ) by each winding of current-balance transformer TX. The recovery function is performed by the leakage $\mathrm{L}$ and the load $\mathrm{C}$ resonance. This mode also includes a current-sharing operation, leading to a reduction of the conduction loss. The equivalent conduction circuit is shown in Fig. 4(c). When the panel voltage decreases from $\mathrm{V}_{\mathrm{S}}$ to zero under $\mathrm{L}-\mathrm{C}$ resonance as in equation (4), the zero current switching (ZCS) condition of $\mathrm{S}_{\mathrm{X} 3}$ (or $\mathrm{S}_{\mathrm{X} 1}$ ) is satisfied. At the end of this mode, $\mathrm{S}_{\mathrm{X} 4}$ (or $\mathrm{S}_{\mathrm{X} 2}$ ) turns on again. The equations of the panel voltage and the current are as follows:

$$
\begin{gathered}
I_{C p}=-\frac{V_{S}}{2 Z_{0}} \sin \omega_{0}\left(t-t_{2}\right) \\
V_{C p}=\frac{V_{S}}{2} \cos \omega_{0}\left(t-t_{2}\right) .
\end{gathered}
$$

- Mode $4\left[\mathrm{t}_{3}<\mathrm{t} \leq \mathrm{t}_{4}\right]$ :

After the resonant current sinks to zero in mode 3, the ZCS condition of $\mathrm{S}_{\mathrm{X} 3}$ (or $\mathrm{S}_{\mathrm{X} 1}$ ) is achieved. When the load voltage reaches the ground, $\mathrm{S}_{\mathrm{X} 4}$ (or $\mathrm{S}_{\mathrm{X} 2}$ ) start to conduct. The load voltage maintains zero voltage until a new operating cycle begins.

Mode 5 - Mode 8 are omitted because they are the same as Mode 1 - Mode 4 except for the switching legs of $S_{Y 1}, S_{Y 2}$, $\mathrm{S}_{\mathrm{Y} 3}$, and $\mathrm{S}_{\mathrm{Y} 4}$.
TABLE I

COMPARISON OF THE NUMBer OF DEVICES

\begin{tabular}{|l|c|c|c|c|}
\hline & Switch & Diode & Magnetics & $\begin{array}{c}\text { Storage } \\
\text { Capacitor }\end{array}$ \\
\hline Webber's & 8 & 8 & 2 Inductor & 4 \\
\hline Proposed & 8 & 4 & 2 transformer* & $0 * *$ \\
\hline
\end{tabular}

** be replaced by input voltage source

\section{B. Clamp circuit}

The resonant inductor $\mathrm{L}$ series-connected with a fourquadrant switch can cause a surge problem when there is no current path for the inductor with the switches turning-off. Then the switches can suffer a device failure induced by a drain-source breakdown at the switching moment [22]. One of the solutions for the problem is to apply a typical voltageclamping circuit.

Fig. 5 shows a Weber's sustain driver circuit to which a voltage-clamping circuit is applied. The circuit is composed of a pair of diodes in a front-to-back scheme, transferring the remaining inductor-current back into the source VS at the auxiliary switches $\left(\mathrm{S}_{\mathrm{X} 1}, \mathrm{~S}_{\mathrm{X} 2}, \mathrm{~S}_{\mathrm{Y} 1}, \mathrm{~S}_{\mathrm{Y} 2}\right)$ turn-off [22]. For a similar but not exactly the same reason, the proposed switchedtransformer ERC needs a clamp circuit. In the proposed scheme, the clamp is located at the tap of the transformer directly connected to the load and the source rather than the switching bridge as shown in Fig. 6. The front-to-back diode pair clamps the resonant voltage at the load by making a current path for the remaining current of the leakage inductor in the tapped transformer. The current path prevents the resonance between the capacitive load and the leakage inductance. According to the direction of the inductor current, one of the diodes turns on and the oscillating load voltage can be clamped either to the $\mathrm{V}_{\mathrm{S}}$ or to the ground. The electrical stresses of the clamp circuits are the same in both ERCs [22].

\section{Device count comparison}

Employing a current-balance transformer, the proposed ERC has an even power-stress for the main devices as well as a reduced part count. Table I shows a comparison of the number of key devices between a conventional Webber's ERC and the proposed ERC. Since 4 diodes in the resonant network are removed, the proposed ERC can be simply implemented and the number of devices is significantly reduced when compared with a conventional Webber's ERC. The resonant inductor can be replaced by the leakage inductance of the transformer, as well. The instantaneous voltage and current stresses of $v_{d s}$ and $i_{d}$ on the 8 power MOSFETs in the proposed scheme are all the same as:

$$
\begin{aligned}
& v_{d s}=\mathrm{V}_{\mathrm{S}} \\
& i_{d}=\mathrm{I}_{\mathrm{Cp}} / 2 \text { (during the conducting mode), } \\
& \text { where } I_{C p}=-\frac{V_{S}}{2 Z_{0}} \sin \omega_{0}\left(t-t_{2}\right)
\end{aligned}
$$

This stress uniformity in the manufacturing elements leads to the same device part selection for an optimal circuit design and significantly contributes to an enormous cost reduction in mass-production for the end-product industry, benefiting from economies of scale. 


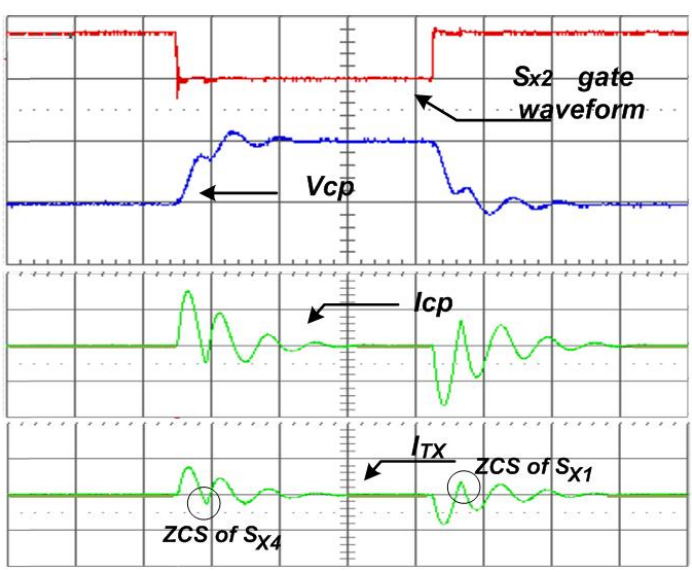

Fig. 7. Experimental result of the proposed ERC hardware with a capacitor $\operatorname{load}(2 \mu \mathrm{s} / \mathrm{div}, 100 \mathrm{~V} / \mathrm{div}, 10 \mathrm{~A} / \mathrm{div})$.

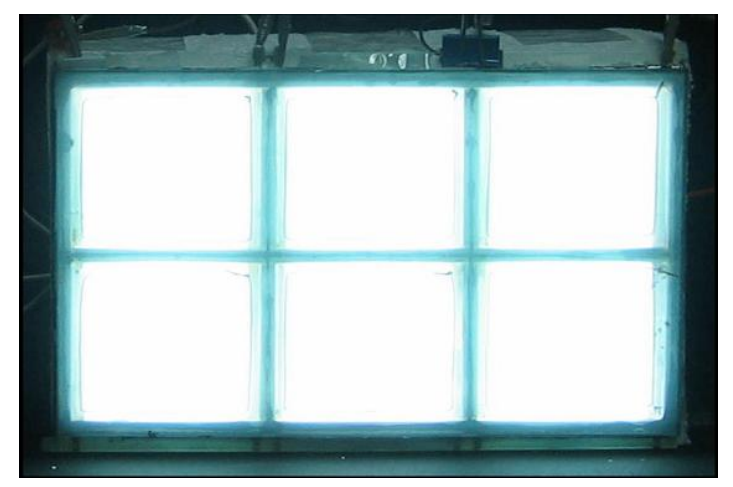

Fig. 8. Picture of a 12-inch MFFL illuminating in full-area [5].

\section{EXPERIMENTAL RESUlTS}

To verify the operation analysis of the proposed ERC, a hardware prototype of the current-balance transformer ERC has been built. As a first experimental test, a capacitor load bank was used for checking the energy-recovery operation. The load capacitance was $88 \mathrm{nF}$, and the switching frequency was $20 \mathrm{kHz}$.

Fig. 7 shows the experimental results of the load current $\left(\mathrm{I}_{\mathrm{Cp}}\right)$, the load voltage $\left(\mathrm{V}_{\mathrm{Cp}}\right)$, and the winding current of the current-balance transformer ( $\left.\mathrm{I}_{\mathrm{TX}}\right)$. As analyzed in a previous section, the waveforms show the charging/discharging current flows to/from the capacitor-load under resonance operation between the transformer inductance and the load capacitance. Also, it is shown that the winding current of the currentbalance transformer $\left(\mathrm{I}_{\mathrm{TX}}\right)$ is almost half of the load current $\left(\mathrm{I}_{\mathrm{Cp}}\right)$. This means that the transformer equally distributes the load current to the switch legs connected on each winding extremity of the primary and secondary sides. The $\mathrm{I}_{\mathrm{Cp}}$ waveform also shows that the magnitude of the positive and negative swings are almost even for a load pulsation, which shows that the electric charges in the capacitive load are recovered back to the source completely. The current spikes which appears when the ZCS operation fails are not shown in this figure (see fig. 2(b), also).

The ERC hardware prototype was implemented, and also tested for an isolation-type industrial application. The application was an AC plasma panel driver for a 12-inch (6-cell)
Mercury-free Flat Fluorescent Lamp (MFFL). Figure 8 shows a photograph of the stable illumination of a single panel of a MFFL in the entire-surface glow-discharge mode.

Fig. 9 shows the experimental results using a 12-inch MFFL under the condition of a $17.5 \mathrm{kHz}$ switching frequency. The leakage inductance of the transformer is designed to be $2.2 \mu \mathrm{H}$ at the switching frequency. To ignite the MFFL, another step-up transformer with turn-ratio of timelstransHour13Minute101:10 is inserted between the current-balance transformer and the load for taking a high firing voltage over $2 \mathrm{kV}$.

Fig. 9(a) shows the switching-voltage waveforms of the gate-source $\left(\mathrm{V}_{\mathrm{gs}}\right)$ and the drain-source $\left(\mathrm{V}_{\mathrm{ds}}\right)$ of the full-bridge MOSFETs. In the figure, when the bottom switch $S_{\mathrm{X} 2}$ turns off, the bridge voltage Vds start to rise with the resonance and the top switch $S_{\mathrm{X} 3}$ turns on in the soft-switching manner. Likewise, when the top switch $\mathrm{S}_{\mathrm{X} 3}$ turns off, the bridge voltage Vds starts to sink with the resonance and the bottom switch $\mathrm{S}_{\mathrm{X} 2}$ turns on in the soft-switching manner. Zero-volatage switching (ZVS) contributes to the switching loss reduction in the MFFL driver.

Fig. 9(b) shows the panel voltage $\left(\mathrm{V}_{\mathrm{Cp}}\right)$, the panel current $\left(\mathrm{I}_{\mathrm{Cp}}\right)$ presenting the MFFL's electrical operating characteristics, and the winding current of the current balance transformer ( $\left.\mathrm{I}_{\mathrm{TX}}\right)$ to conform the current sharing action between the windings. The MFFL is a dielectric barrier discharge (DBD) panel with two soda-lime glasses, representing capacitive load characteristics during the charging/discharging modes [23], [24]. Consequently, the current waveform of the MFFL is shown as a superposition of the sustain (glow) discharge current and the pulse transition current. Even though there are some parasitic effects from another transformer, the recovery action of the driver can be conformed as well.

Also, the experimental result shows that the winding current is almost half of the load current $\left(\mathrm{I}_{\mathrm{Cp}}\right)$ as mentioned in a previous section. In the case of a conventional Webber's ERC, the sustain and transition currents are fully conducting through a single switch. On the other hand, in the proposed ERC, the panel current is split up by each winding of the current-balance transformer, thus the conduction loss is also theoretically decreased by almost half. Fig. 9(c) shows the long-term MFFL-driving waveforms operating in the AC manner. The recovery current can be checked more clearly than in the previous figures.

In order to validate the performance of the proposed ERC, it was compared with a conventional ERC in terms of luminance efficiency. Fig. 10 shows luminance-efficiency curves at some different brightness levels. In the case of the Webber's ERC, the luminance efficiency is at its maximum at $24.51 \mathrm{~m} / \mathrm{W}$. On the other hands, when the proposed ERC was applied, the maximum luminance efficiency is $28.21 \mathrm{~m} / \mathrm{W}$ at $4000 \mathrm{~cd} / \mathrm{m} 2$. In most of the operating region, the proposed ERC has a higher efficiency than that of the Webber's ERC even though the curve goes down as the luminance increases, due to the hard switching turn-on with a high input voltage. The experimental results indicate that under a low luminance, the luminance efficiency was increased by $15 \%$ as the ordinary MFFL efficiency trend shows. From the results, it can be seen 


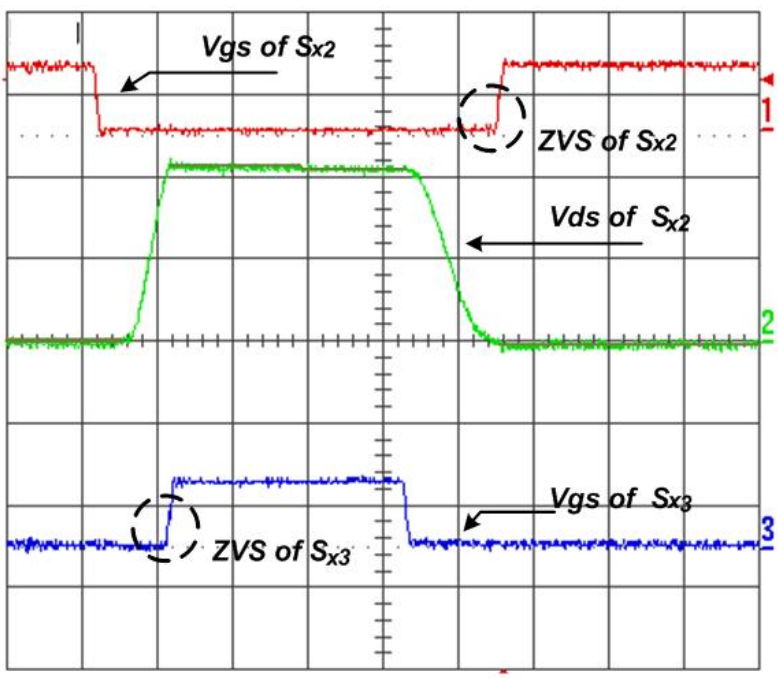

(a) Switch voltage waveforms, ch.1: [20V/div], ch. 2: [100V/div], ch. 3: [20V/div], $0.5[\mu \mathrm{s} / \mathrm{div}]$.

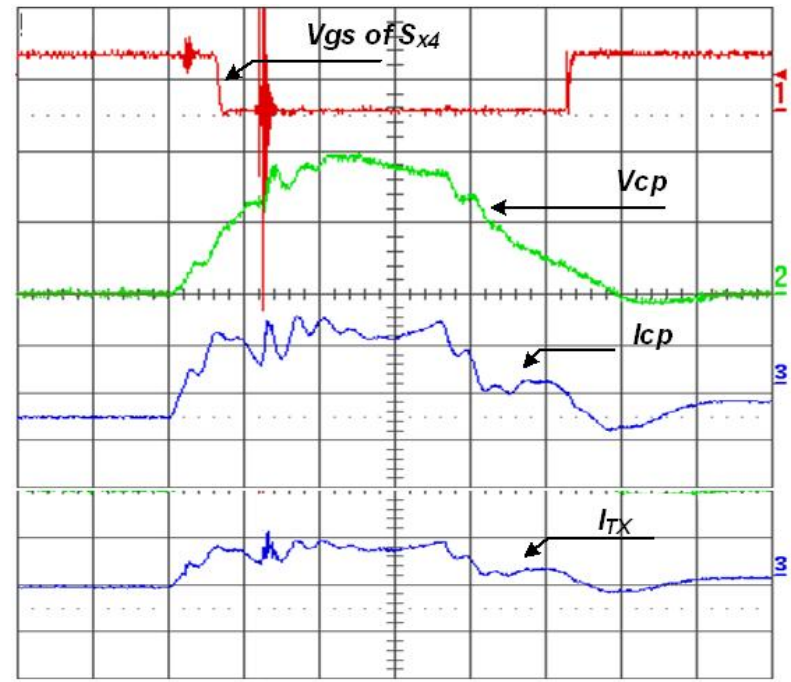

(b) Current sharing, ch.1: [20V/div], ch. 2: [1kV/div], ch. 3: [2A/div], $0.5[\mu \mathrm{s} / \mathrm{div}]$.

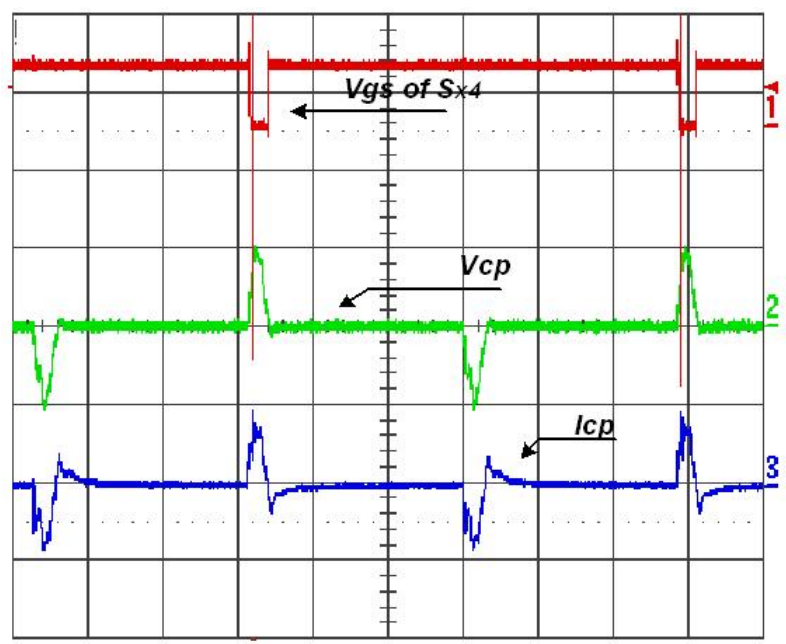

(c) AC driving: panel voltage $\left(\mathrm{V}_{\mathrm{Cp}}\right)$ and current $\left(\mathrm{I}_{\mathrm{Cp}}\right)$, ch.1: [20V/div], ch. 2: [2kV/div], ch. 3: [200mA/div], $10[\mu \mathrm{s} / \mathrm{div}]$.

Fig. 9. Experimental results of the proposed ERC with a 12-inch MFFL panel.

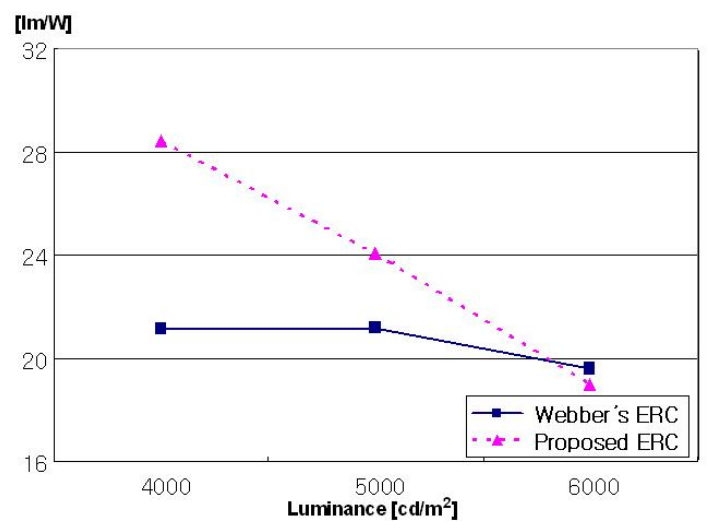

Fig. 10. Luminance efficiency comparison.

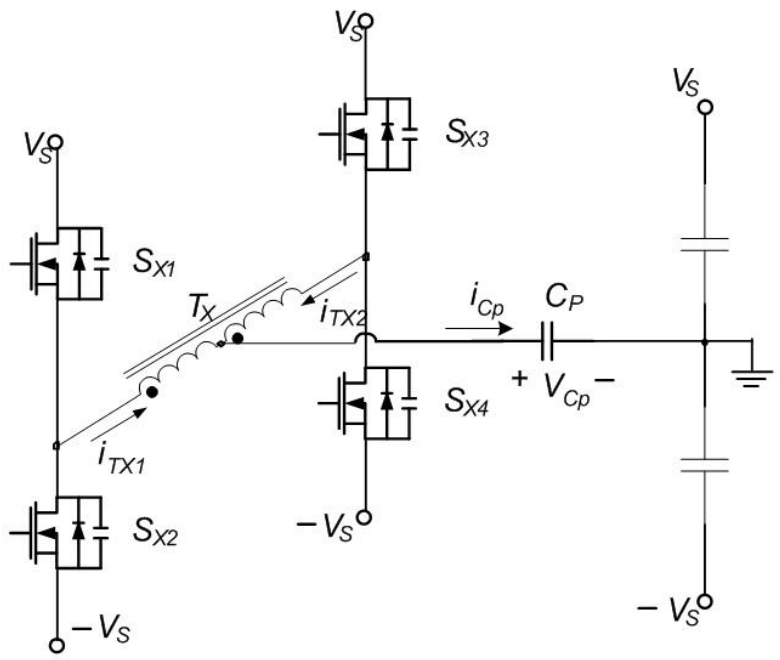

(a) Circuit diagram of the two-level ERC in the proposed scheme.

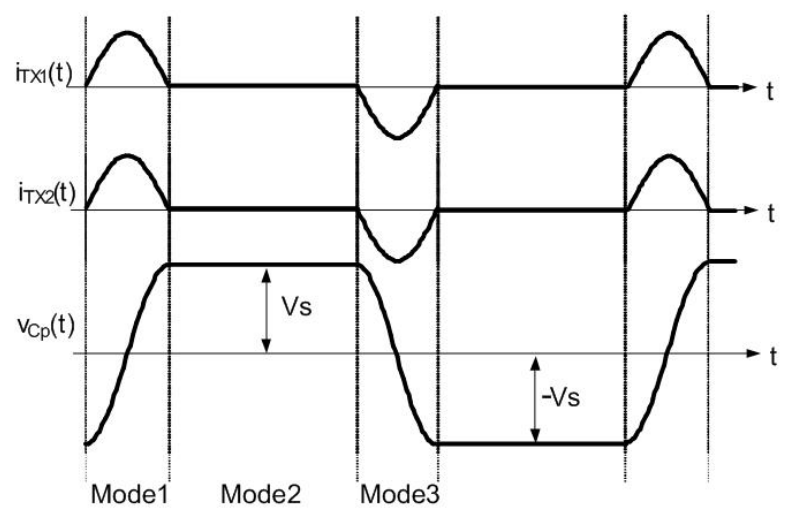

(b) Key waveforms (Vcp: panel voltage, $\mathrm{i}_{\mathrm{rx} 1}$ :Primary current, $\mathrm{i}_{\mathrm{rx} 2}$ : Secondary current).

Fig. 11. Two-level sustain driver with a balance transformer.

that the proposed ERC is very suitable for some capacitive load applications, especially plasma displays and lightings.

\section{Two Level Sustain Driver}

The proposed balace-transformer ERC can be modified to a two-level sustain driver. Two-level means that the load has a two-kind voltage level such as $\mathrm{V}_{\mathrm{s}}$ and $-\mathrm{V}_{\mathrm{s}}$, instead of $\mathrm{V}_{\mathrm{s}}, 0$, and $-\mathrm{V}_{\mathrm{s}}$. Since two levels can be obtained by the 
simultaneous energy-recovery action of each resonance leg, one of the full-bridge legs including the transformer can be integrated into the other leg as shown in Fig. 11(a). The other point of the capacitive load is always tied up at the ground. Two-level drivers are very suitable for very high-frequency sustain drivers since the ERC can reduce the transition time of the panel polarity due to the simultaneous recovery of the reactive energy on both sides of the panel [22], [25].

The two-level driver is a simplified version of a three-level ERC employing only single bridge leg, which results in a reduction by half of the part count and the manufacturing cost when compared to the original one. The gating sequence is exactly the same as the half cycle of the entire one shown in Fig. 3, thus the operating modes of the two-level are exactly the same as the aforementioned three-level operation except modes 4 and 8 indicating the zero level. The clamp circuit introduced in the previous section can be employed in this ERC as well for preventing the voltage oscillations caused by the resonance between the leakage inductance and the capacitive load. In terms of part count, this two-level version is also very feasible as a cost-effective sustain driver for AC plasma display/lightings.

The ERC can be more cost-competitive by simplifying it into single full-bridge leg, which leads to a significant reduction in the part count.

\section{Conclusions}

This paper has proposed a new energy-recovery circuit for AC driving with a capacitive load using a current-balance transformer. The proposed ERC has some advantages such as an improvement in luminance efficiency, a cost reduction and a simple circuit architecture. The circuit can improve the system efficiency through an energy-recovery function and a reduction of the switching loss by zero-voltage switching. The current sharing action with a current-balance transformer also contributes to the efficiency improvement through a reduction of the conduction loss. Furthermore, the proposed ERC needs no extra diodes for the resonance path of the conventional circuit. The lower device count as well as the identical voltage/current ratings of all the switching devices makes the ERC more competitive from the perspective of manufacturing cost. The operating principles of the proposed ERC are presented through mode analysis and verified with a hardware experiment using a 12-inch MFFL. In terms of luminance efficiency, the proposed scheme has better performance than the conventional one in the overall region of a 4000 to $6000 \mathrm{~cd} / \mathrm{m} 2$ brightness level, the maximum point of which is greater than $281 \mathrm{~m} / \mathrm{W}$ at $4000 \mathrm{~cd} / \mathrm{m} 2$. From the experimental results, it can be seen that the proposed ERC can be a good alternative for some AC-driving applications with capacitive loads due to its low cost and high performance.

\section{ACKNOWLEDGMENT}

This work was supported by the Human Resources Development Project of the Korea Insitute of Energy Technology Evaluation and Planning(KETEP) grant funded by the Ministry of Knowledge Economy, Republic of Korea (No. 20104010100610).

\section{REFERENCES}

[1] S. Mikoshiba, "Xe discharge backlights for LCDs," SID 01 Digest, pp. 286-289, 2001.

[2] M. Ilmer, R. Lecheler and M. Seibold, "Efficiency enhancement of hgfree fluorescent PLANON backlights by CAF,' IDW '99, pp. 1107-1108, 1999.

[3] T. Shiga, S. Mikoshiba and S. Shinada, "No-mercury flat discharge lamp for LCD backlighting," IDW '99, pp. 347-350, 1999.

[4] Y. Ikeda, T. Shiga, S. Mikoshiba, "Mercury-free, simple-structured flat discharge LCD backlights Ranging from 0.5 to 5.2-in. diagonals," SID, pp. 938-941, 2000.

[5] Joung-Hu Park, Jong-Bok Baek, and Bo-Hyung Cho, "Electrical feedback control for driving mercury-free flat fluorescent lamp," Journal of the Society for Information Display, Vol. 16, Issue 2, pp. 367-373, Feb. 2008.

[6] Ju kwang Lee, Jaechul Jung, Byungjoo Oh, Inwoo Seo, Joongkyun Kim and Ki-Woong Whang, "The electro-optic characteristics of MFFL," SID, pp. 1422-1424, 2006.

[7] L. F. Weber and K. W. Warren, "Power efficient sustain driver and address drivers for plasma display panel," U. S. Patent 4886 349, Sep. 1989.

[8] D. Y. Lee, J. H. Yang, and B. H. Cho, "Novel energy-recovery driving circuit for plasma display panel using regenerative transformer," PESC03, Vol. 2, pp. 656-659, Jun. 2003.

[9] W. S. Kim, S. Y. Chae, B. C. Hyun, D. Y. Lee, and B. H. Cho, "A cost effective PDP sustainer using two-winding transformer with hybrid operation," Applied Power Electronics Conference, pp. 294-298, 2007.

[10] L. Jun-Young, K. Jin-Sung, J. Nam-Sung, and Bo-Hyung Cho, "The current injection method for AC plasma display panel (PDP) sustainer," IEEE Transactions on Industrial Electronics, Vol. 51, pp. 615-624, Jun. 2004.

[11] Ling-Guo Meng, Zhi-Hu Liang Chun-Liang Liu, "Energy recovery circuit with auxiliary power supply for AC plasma display panel," IEEE Transactions on Consumer Electronics, Vol. 53, No. 2, pp. 765- 768, May 2007

[12] Feel-soon Kang, "Series resonant sustain driver for AC plasma display," IEEE Transactions on Consumer Electronics, Vol. 54, No. 3, pp. 14151421, Aug. 2008.

[13] R. Chung-Wook, "Novel plasma display driver with low voltage/current device stresses," IEEE Transactions on Consumer Electronics, Vol. 49, Issue 4, pp. 1360-1366, Nov. 2003.

[14] Kang-Hyun Yi, Sang-Kyoo Han, Seong-Wook Choi, Chong-Eun Kim, and Gun-Woo Moon, "A simple ZVZCS sustain driver for a plasma display panel," Journal of Power Electronics, Vol.6, No.4, pp. 298-306, Oct. 2006.

[15] Dong-Myung Lee, "A novel driver for plasma displays using alternative concept for generating reset voltage waveform," IEEE Transactions on Consumer Electronics, Vol. 53, No. 4, Nov. 2007.

[16] Jun-Young Lee, "Dual path magnetic-coupled AC-PDP sustain driver with low switching loss," Journal of Power Electronics, Vol.6, No.3, pp. 205-213, Jul. 2006.

[17] Woo-Jin Lee, Seong-Wook Choi, Chong-Eun Kim, Gun-Woo Moon, "A new PWM-controlled quasi-resonant converter for a high efficiency PDP sustaining power module," Journal of Power Electronics, Vol.7, No.1, pp. 28-37, Jan. 2007

[18] Y. Jin Ho, K. Joong Kyun, and W. Ki Woong, "An energy recovery circuit for AC plasma display panel with series CLC resonance-SER1," IEEE Transactions on Consumer Electronics, Vol. 51, pp. 718-724, May 2005.

[19] Baek-Kaeng Lee, Hee-Jun Kim, "High-efficiency ballast for HID lamp using soft-switching multi-level inverter," Journal of Electrical Engineering \& Technology, Vol. 2, No. 3, pp. 373 378, Sep. 2007.

[20] Jin-Yong Bae, Yong Kim, "A study on the secondary rectificationmethods for the three-level converter," Journal of Electrical Engineering \& Technology, Vol. 2, No. 1, pp. 81 88, Mar. 2007.

[21] W.S. Kim, P. Agarwal, S.Y. Chae, B.H. Cho, and D.Y. Lee, "A new energy recovery circuit for the PDP sustainer using the auxiliary transformer," SID 06 DIGEST, pp. 623-626, 2006.

[22] J. H. Park, Jongwon Shin, Woosup Kim and B. H. Cho, "Cost-effective sustain driver employing a new four-quadrant switch cell for AC plasma display," IEEE Transactions on Consumer Electronics, Vol. 55, No. 4, pp. 2040-2047, Nov. 2009.

[23] Joung-Hu Park, Bo-Hyung Cho, Ju-Kwang Lee, Ki-Woong Whang, "Performance evaluation of 2-dimensional light source using mercuryfree flat fluorescent lamps for LCD backlight applications," Journal of Power Electronics, Vol.9, No 2, pp. 164 172, Mar. 2009. 
[24] Joung-Hu Park, Jong-Bok Baek, Bo-Hyug Cho, "Current-sourced Pushpull Inverter for Mercury-free Flat Fluorescent Lamp Driving," SID, pp.1560-1563, May 2008.

[25] S. W. Choi, S. K. Han, G. W. Moon, H. C. Yang and Y. H. Cho, "A study on high frequency sustaining driver for improving luminance efficiency of AC-PDP," Power Electronics Specialist Conf., pp. 96-112, 2005.

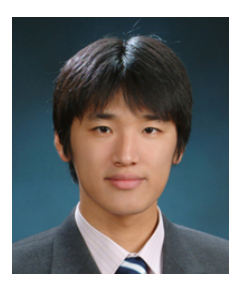

Jong-Bok Baek received his B.S. from the Electrical Engineering and Computer Science department of Kyungpook National University, Daegu, Korea in 2007. He is currently a Ph.D.'s student at Seoul National University. His interests include the analysis and design of DSP-based switching converters, and the driver circuits of PDP displays.

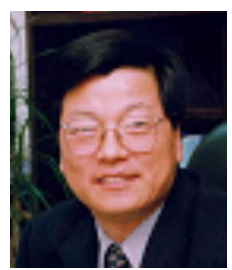

Bo-Hyung Cho received his B.S. and M.E. in Electrical Engineering from the California Institute of Technology, Pasadena, and his Ph.D. also in Electrical Engineering, from Virginia Polytechnic Institute and State University (Virginia Tech), Blacksburg, Virginia. Prior to his research at Virginia Tech, he worked for two years as a member of the technical staff in the Power Conversion Electronics Department, TRW Defense and Space System Group, where he was involved in the design and analysis of spacecraft power processing equipment. From 1982 to 1995, he was a Professor in the Department of Electrical Engineering, Virginia Tech. He joined the School of Electrical Engineering, Seoul National University, Seoul, Korea in 1995 and he is presently a Professor. His main research interests include power electronics, modeling, analysis and control of spacecraft power processing equipment, power systems for space stations and space platforms, and distributed power systems. Dr. Cho was a recipient of the 1989 Presidential Young Investigator Award from the National Science Foundation. He is a member of Tau Beta Pi.

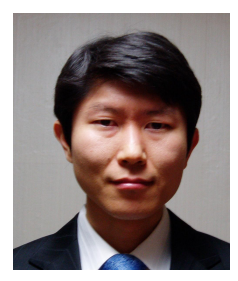

Joung-Hu Park received his B.S., M.S., and Ph.D. from the Electrical Engineering and Computer Science department of Seoul National University, Seoul, Korea in 1999, 2001 and 2006, respectively. He is currently an Assistant Professor at Soongsil University, Seoul, Korea. His interests include the analysis and design of high-frequency switching converters, driver circuits for PDP displays, and piezoelectric transformer power applications. 